\title{
Revealing the Structure and Oxygen Transport at Interfaces in Complex Oxide Heterostructures via ${ }^{17} \mathrm{O}$ NMR Spectroscopy
}

\author{
Michael A. Hope, Bowen Zhang, Bonan Zhu, David M. Halat, Judith L. MacManus-Driscoll, \\ and Clare P. Grey*
}

Cite This: Chem. Mater. 2020, 32, 7921-7931

Read Online

\section{ACCESS | Llll Metrics \& More | 回 Article Recommendations | (s) Supporting Information}

ABSTRACT: Vertically aligned nanocomposite (VAN) films, comprising nanopillars of one phase embedded in a matrix of another, have shown great promise for a range of applications due to their high interfacial areas oriented perpendicular to the substrate. In particular, oxide VANs show enhanced oxide-ion conductivity in directions that are orthogonal to those found in more conventional thin-film heterostructures; however, the structure of the interfaces and its influence on conductivity remain unclear. In this work, ${ }^{17} \mathrm{O}$ NMR spectroscopy is used to study $\mathrm{CeO}_{2}-\mathrm{SrTiO}_{3}$ VAN thin films: selective isotopic enrichment is combined with a lift-

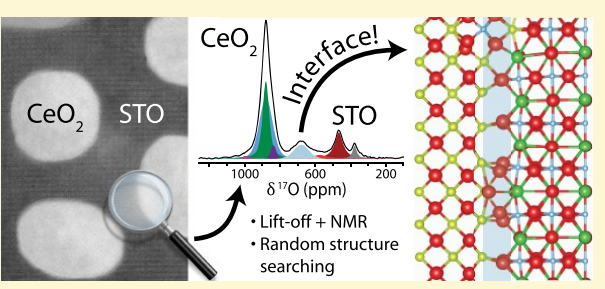
off technique to remove the substrate, facilitating detection of the ${ }^{17} \mathrm{O}$ NMR signal from single atomic layer interfaces. By performing the isotopic enrichment at variable temperatures, the superior oxide-ion conductivity of the VAN films compared to the bulk materials is shown to arise from enhanced oxygen mobility at this interface; oxygen motion at the interface is further identified from ${ }^{17} \mathrm{O}$ relaxometry experiments. The structure of this interface is solved by calculating the NMR parameters using density functional theory combined with random structure searching, allowing the chemistry underpinning the enhanced oxide-ion transport to be proposed. Finally, a comparison is made with $1 \% \mathrm{Gd}$-doped $\mathrm{CeO}_{2}-\mathrm{SrTiO}_{3}$ VAN films, for which greater NMR signal can be obtained due to paramagnetic relaxation enhancement, while the relative oxide-ion conductivities of the phases remain similar. These results highlight the information that can be obtained on interfacial structure and dynamics with solid-state NMR spectroscopy, in this and other nanostructured systems, our methodology being generally applicable to overcome sensitivity limitations in thin-film studies.

$\mathrm{O}$ xide thin films exhibit an incredible variety of functional properties, which have been widely applied in electronic, magnetic, and energy devices. Oxide heterostructures combine two or more different phases, the interfaces of which induce novel or enhanced functional properties due to their unique local environments. ${ }^{1-4}$ In particular, vertically aligned nanocomposite (VAN) films, comprising nanopillars of one phase embedded in a matrix of another, have shown great promise for applications as high-temperature superconductors, ${ }^{5-8}$ ferroelectrics, ${ }^{9-12}$ multiferroics, ${ }^{13}$ data storage media, ${ }^{14,15}$ and electronic/ionic conductors. ${ }^{16-18}$ Unlike conventional planar multilayered heterostructures, the interfaces in VAN films are perpendicular to the substrate, resulting in significantly higher interface-to-volume ratios, more uniform strain, and control over the orthogonal transport properties, ${ }^{4,19}$ leading to their potential use in, for example, micron-sized fuel cells. A comprehensive understanding of the interfacial structures in oxide thin-film heterostructures is nevertheless required to optimize their design for these various applications, which is very experimentally challenging: the chemical composition, atomic arrangement, and electronic structure at the interfaces can be significantly different to those of the bulk, being influenced by a number of factors such as the lattice mismatch and growth conditions. Previous microscopy-based character- ization techniques ${ }^{18,20-23}$ have the major drawbacks that (i) only the one-dimensional intersection of the interface with the external surface is accessible (without ion milling) and (ii) it is only feasible to study a very small region of the sample; such results may not, therefore, be representative of the "bulk" interfaces in the sample.

Here, we study $\mathrm{CeO}_{2}-\mathrm{STO}\left(\mathrm{STO}=\mathrm{SrTiO}_{3}\right)$ VAN films; these $^{17,18}$ and related films ${ }^{24}$ have been shown to have greatly enhanced oxide-ion conductivity, which is a key property for technologies such as solid oxide fuel cells, ${ }^{25}$ catalysts, ${ }^{26}$ and ion switches, ${ }^{27}$ but the mechanism that gives rise to this increased conductivity remains unclear. Scanning transmission electron microscopy (STEM) images (reproduced in Figure 1a) of Smdoped- $\mathrm{CeO}_{2}-\mathrm{STO}$ VAN films, grown using the same procedure as the $\mathrm{CeO}_{2}-\mathrm{STO}$ VAN films studied in this work, show nanopillars of around $20-30 \mathrm{~nm}$ in diameter embedded in an STO matrix. The relative orientation of the

Received: June 26, 2020

Revised: August 18, 2020

Published: August 19, 2020 
(a)

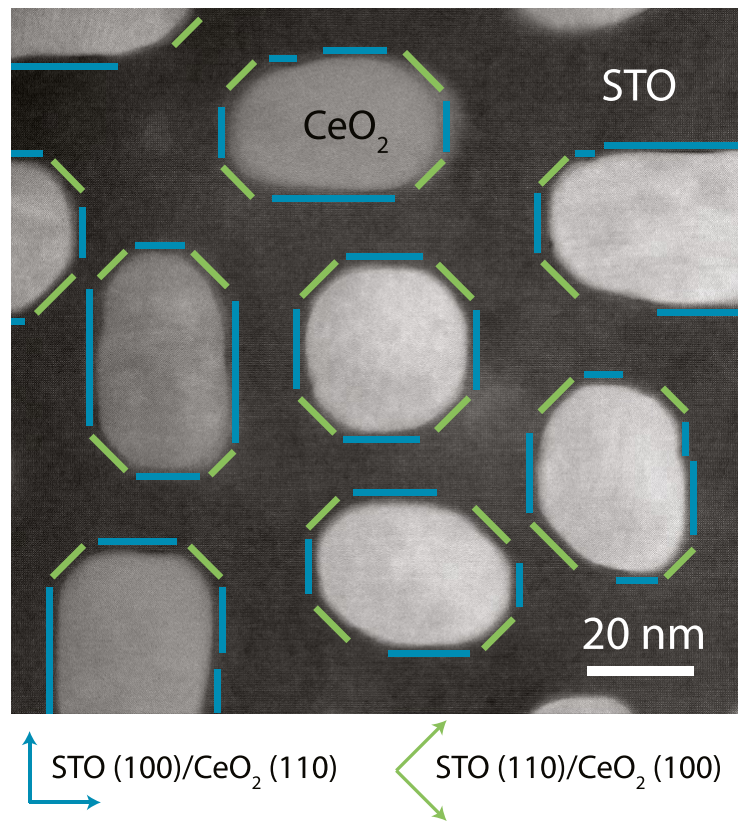

(b) $0^{\circ}$ Interface: STO (100)/ $\mathrm{CeO}_{2}(110)$
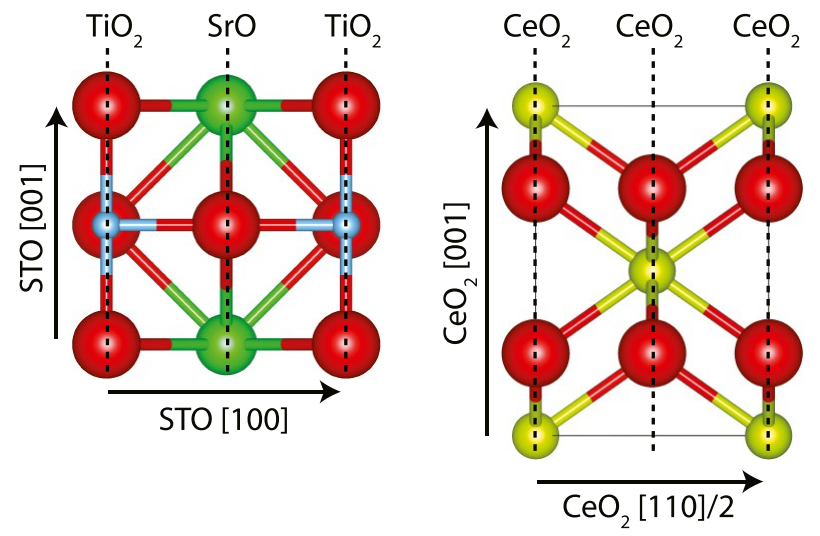

(c) $45^{\circ}$ Interface: STO (110)/ $\mathrm{CeO}_{2}(100)$
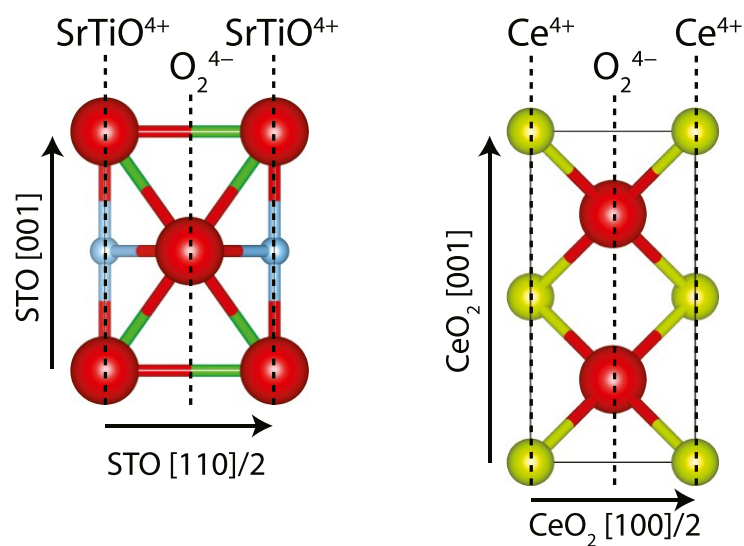

Figure 1. (a) STEM image of a 20 atom $\%$ Sm-doped-CeO $\mathrm{C}_{2}-\mathrm{STO}$ VAN film, showing the two dominant types of interface, reproduced in part with permission from ref 30, Copyright 2019 Zhu et al., AIP publishing (www.creativecommons.org/licenses/by/4.0/). (b, c) Schematics of the orientations of the STO and $\mathrm{CeO}_{2}$ structures at the two types of interface. The elements are colored as follows: O: red, Ti: blue, Sr: green, and Ce: yellow. phases is dictated by the epitaxy on the STO substrate and two major types of interface can be distinguished: $\mathrm{CeO}_{2}(110) /$ STO(100), referred to as the $0^{\circ}$ interface, and $\mathrm{CeO}_{2}(100) /$ STO(110), referred to as the $45^{\circ}$ interface, in a ratio of $\sim 3: 1$; there are also some more poorly defined, rounded, interfaces, and steps, which complicate the analysis (see Supporting Information Note 1 for quantification of the interfaces). STO has a perovskite structure $(P m \overline{3} m)$, which in the $\langle 100\rangle$ directions comprises alternating planes with stoichiometries of $\mathrm{SrO}$ and $\mathrm{TiO}_{2}$, respectively (Figure $1 \mathrm{~b}$, left), whereas in the $\langle 110\rangle$ directions, there are alternating planes of $\mathrm{SrTiO}^{4+}$ and $\mathrm{O}_{2}{ }^{4-}$ (Figure 1c, left). $\mathrm{CeO}_{2}$, on the other hand, has a fluorite structure $(F m \overline{3} m)$ : in the $\langle 100\rangle$ directions, there are alternating planes of $\mathrm{Ce}^{4+}$ and $\mathrm{O}_{2}{ }^{4-}$, and in the $\langle 110\rangle$ directions, all of the planes have the same stoichiometry of $\mathrm{CeO}_{2}$, but with an alternating $\mathrm{Ce}^{4+}$ position (Figure $1 \mathrm{~b}, \mathrm{c}$, right). In both cases, the ratio of the lattice parameters (3.905 $\AA$ for STO, $5.412 \AA$ for $\mathrm{CeO}_{2}$ ) results in a matching of 7 STO to $5 \mathrm{CeO}_{2}$ unit cells. ${ }^{28-30}$ While such analyses can be used to determine which planes from the two materials lie parallel to each other at the interfaces, it is nontrivial to identity the local structure and composition at the interfaces and to quantify the extent of disorder/cation mixing.

Solid-state NMR is a powerful technique to study local structure and dynamics, and for oxide materials, ${ }^{17} \mathrm{O}$ NMR in particular is extremely sensitive to local distortions caused by, e.g., surfaces, ${ }^{31-34}$ substituents, ${ }^{35-37}$ and other defects. ${ }^{38-40}$ Furthermore, oxygen motion and oxide-ion conductivity can be investigated via ${ }^{17} \mathrm{O}$ NMR relaxometry. ${ }^{35,37,41}$ However, NMR and ${ }^{17} \mathrm{O}$ NMR in particular suffer from low sensitivity; ${ }^{42}$ the challenge of acquiring spectra with a sufficient signal-tonoise ratio (SNR) is exacerbated when studying thin films due to the extremely low sample mass and further compounded for the study of interfaces, which, as two-dimensional (2D) entities, inherently comprise only a fraction of the sample volume. Taking these factors together, it can be seen that ${ }^{17} \mathrm{O}$ NMR studies of interfaces in thin films are extremely challenging. There is, however, a redeeming feature: since the nanopillars are approximately $20-30 \mathrm{~nm}$ in diameter, the sample actually contains a comparatively large interfacial area $\left(\sim 10^{8} \mathrm{~m}^{2} \cdot \mathrm{m}^{-3}\right.$ or $\sim 1 \%$ of the thin film assuming an interfacial width of $2-3 \AA$ ); consequently, these are ideal samples for the study of interfacial structure.

A further impediment to the study of thin films by NMR is the presence of the substrate, which leads to significant dilution of the sample, typically by three to five orders of magnitude. There is considerable benefit to separating the thin film from the substrate, and in this work, a lift-off procedure was therefore developed, shown in Figure S1 and described in detail in the methods, which combines the water-soluble buffer layer method of $\mathrm{Lu}$ et $\mathrm{al}^{43}$ and the polymer-transfer layer method of Liang et al. ${ }^{44}$ This permits substrate-free thin films to be obtained and transferred into small volume, fast magic angle spinning (MAS), $1.3 \mathrm{~mm}$ outer diameter rotors.

It can be challenging to interpret the chemical shifts in NMR spectra a priori and directly derive structural information, particularly in complicated systems. Instead it has been shown to be particularly effective to combine NMR spectroscopy with density functional theory (DFT) calculations: the NMR parameters are calculated for different possible structures, which are then compared with the experimental spectra to determine which is most consistent. ${ }^{4-47}$ The parameters cannot simply be calculated, however, if the structure in 
question is not known, such as at an interface; this hurdle can be overcome using random structure searching (RSS) or ab initio RSS (AIRSS). ${ }^{30,48}$ In RSS, the atomic positions of some or all of the atoms in the structure are randomized, before being allowed to relax into a local low-energy arrangement; this process is repeated a sufficient number of times such that the resulting lowest-energy structures are probable candidates for the true structure(s).

Using the aforementioned lift-off procedure and selective ${ }^{17} \mathrm{O}$ enrichment, the ${ }^{17} \mathrm{O}$ MAS NMR spectra of the $\mathrm{CeO}_{2}-$ STO VAN films reveal the signal from a single anionic layer at each interface. The relative oxide-ion conductivity of the interface and bulk components is probed by varying the temperature of isotopic ${ }^{17} \mathrm{O}$ enrichment, and NMR relaxometry is used to demonstrate the presence of motion at the interface. Furthermore, the interfacial structure is determined by comparison with the NMR parameters calculated using DFT for different possible structures derived from RSS. Overall, the NMR spectra unveil the interfacial structure and dynamics in the VAN films, and this methodology should prove generally applicable to other thin-film systems.

\section{RESULTS AND DISCUSSION}

${ }^{17} \mathrm{O}$ NMR Spectra. Figure 2a shows the ${ }^{17} \mathrm{O}$ NMR spectrum of the $\mathrm{CeO}_{2}-\mathrm{STO}$ VAN lift-off thin films, enriched with ${ }^{17} \mathrm{O}$ at $450{ }^{\circ} \mathrm{C}$. The $\mathrm{CeO}_{2}$ signal, observed at $879 \mathrm{ppm}$, comprises a sharper and a broader component; the former are ascribed to bulk-like $\mathrm{CeO}_{2}$ environments near the core of the nanopillars (bulk $\mathrm{CeO}_{2}$ exhibits a very sharp ${ }^{17} \mathrm{O}$ resonance at $877 \mathrm{ppm}^{32,49}$ ) and the latter to environments nearer an interface, which are less well defined. The STO signal is observed at $466 \mathrm{ppm}^{50}$ and the $\mathrm{ZrO}_{2}$ of the rotor can be seen at $377 \mathrm{ppm}^{51}$. Between the $\mathrm{CeO}_{2}$ and STO signals, a broad resonance can clearly be observed centered at $680 \mathrm{ppm}$, which is assigned to oxygen ions at the $\mathrm{CeO}_{2}-\mathrm{STO}$ interface. The $\mathrm{CeO}_{2}$ signal also appears to be asymmetric, corresponding to resonances at $837 \mathrm{ppm}$ and approximately $1000 \mathrm{ppm}$; these are attributed to interfacial environments, which are $\mathrm{CeO}_{2}$-like. Furthermore, there is some intensity at $575 \mathrm{ppm}$ ascribed to STO-like interfacial environments. The inclusion of these minor signals in the deconvolution is based on the environments predicted by DFT calculations, vide infra, but was nevertheless found to improve the fits. The short recycle delay of $0.1 \mathrm{~s}$ somewhat suppresses the bulk signals relative to the more distorted, disordered, and/or dynamic interfacial signals, allowing the latter to be more easily observed, since the spinlattice $\left(T_{1}\right)$ relaxation constants of pure bulk $\mathrm{CeO}_{2}$ and STO are ca. 300 and $125 \mathrm{~s}$, respectively (Figures S2 and S3); the short recycle delay, however, precludes quantitative comparison of the signal intensities.

For eighteen $\sim 1 \mu \mathrm{m}$ thick $0.5 \mathrm{~cm}^{2}$ thin films, there is a total volume of just under $1 \mu \mathrm{L}$, although transfer losses of around a factor of two, or greater, are expected. This corresponds to a sample mass of $\sim 3 \mathrm{mg}$ and the region of interest, i.e., the interface, constitutes only $\sim 0.03 \mathrm{mg}$; given the extremely low active mass, it is remarkable to obtain a high-quality ${ }^{17} \mathrm{O}$ NMR spectrum in under a day $(\mathrm{SNR}=24)$. A second sample containing only four lift-off $\mathrm{CeO}_{2}-\mathrm{STO}$ VAN films, rather than the eighteen used for Figure 2a, shows similar signals but took significantly longer to record (5 days, Figure S4).

Structure of the Interface. To interpret the spectral signatures of the VAN films, the interfaces were investigated using DFT. The major $0^{\circ}$ interface has previously been studied

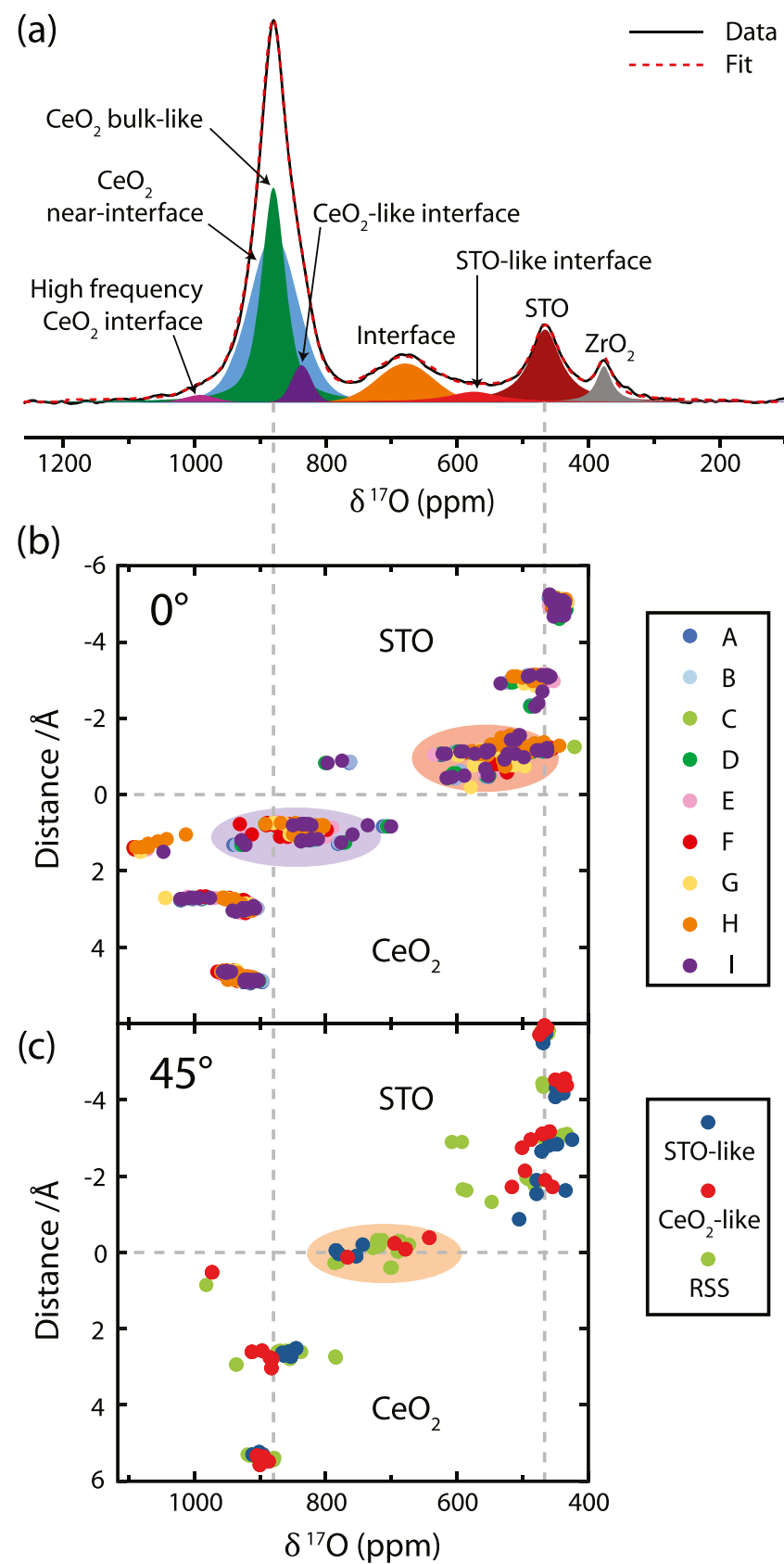

Figure 2. (a) ${ }^{17} \mathrm{O}$ NMR spectrum of $\mathrm{CeO}_{2}-\mathrm{STO}$ nanopillar lift-off films enriched at $450{ }^{\circ} \mathrm{C}$, recorded at $9.40 \mathrm{~T}$ and $50 \mathrm{kHz}$ MAS using a Hahn echo pulse sequence with a single rotor period delay, a $0.1 \mathrm{~s}$ recycle delay, and 800000 scans $(22 \mathrm{~h})$. The spectrum has been deconvoluted using Voigt functions. (b, c) DFT-calculated isotropic shifts as a function of distance from the interface for different predicted interfacial structures: (b) $0^{\circ}$ interface, low-energy structures (A-I); (c) $45^{\circ}$ interface, three structures-STO- and $\mathrm{CeO}_{2}$-like interfaces of the simple model and a low-energy structure with an intermediate stoichiometry found from random structure searching (RSS).

in depth using RSS to find possible interfacial structures; in these calculations, the final STO layer at the interface was chosen to have the stoichiometry $\mathrm{TiO}_{2}$ on the basis of STEM analysis. ${ }^{30}$ As shown in Figure $1 \mathrm{~b}$, the planes which meet at this interface contain both metal cations and oxide anions; to avoid like-charged ions coming into close proximity, there must be significant structural rearrangement at this interface. 
$0^{\circ}$ Interface

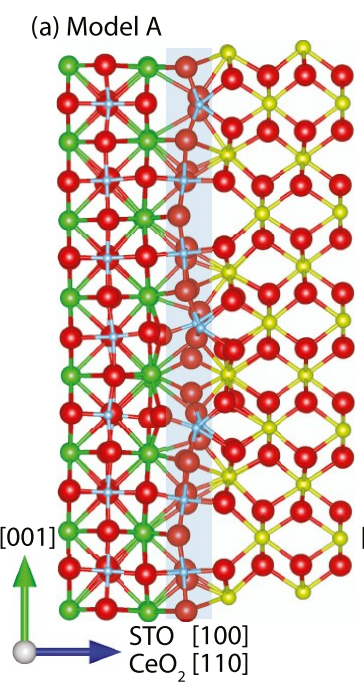

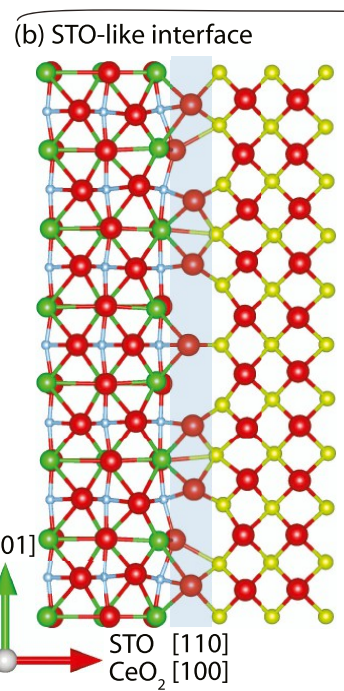

$45^{\circ}$ Interfaces

(c) $\mathrm{CeO}_{2}$-like interface

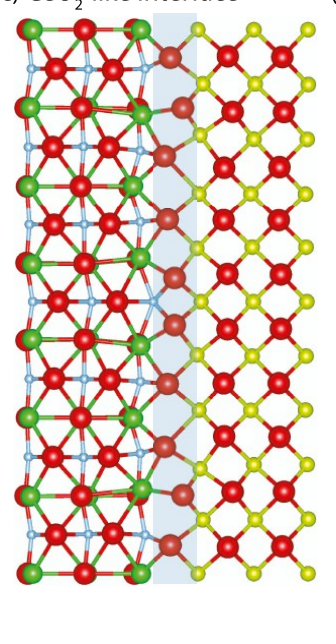

(d) Interface from RSS

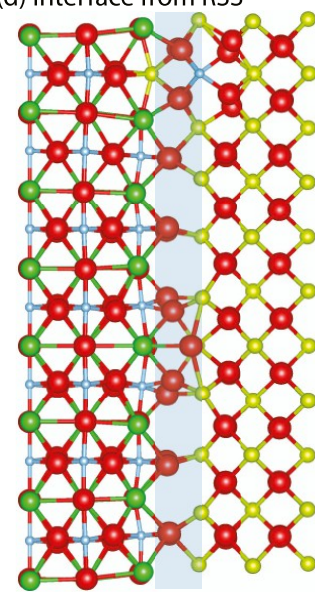

Figure 3. Model structures for the STO- $\mathrm{CeO}_{2}$ interfaces. (a) Model A for the $0^{\circ}$ interface found from $\mathrm{RSS} .{ }^{30}$ (b, c) STO- and CeO $\mathrm{S}_{2}$-like interfaces from the simple model for the $45^{\circ}$ interface. (d) $45^{\circ}$ interface found from RSS. The elements are colored as follows: O: red, Ti: blue, Sr: green, and Ce: yellow.

The ${ }^{17} \mathrm{O}$ NMR parameters were calculated using DFT for nine of the lowest energy predicted $0^{\circ}$ interfaces (Figure $2 \mathrm{~b}, \mathrm{~A}-\mathrm{I}$, the structures can be found a t DOI: $10.24435 /$ materialscloud:2019.0025/v1; as an example, structure $A$ is shown in Figure 3a).

For the two atomic layers closest to the $0^{\circ}$ interface, significant deviations are seen from the bulk chemical shifts; there is a large spread of values, but shifts for the layer on the $\mathrm{CeO}_{2}$ side are centered closer to the bulk $\mathrm{CeO}_{2}$ shift, at around $820 \mathrm{ppm}$, and those for the layer on the STO side are centered closer to bulk STO, at around $580 \mathrm{ppm}$. There are also some environments predicted on the $\mathrm{CeO}_{2}$ side of the interface at higher frequencies $>1000 \mathrm{ppm}$; these arise from three-fold coordinated (i.e., undercoordinated) $\mathrm{CeO}_{2}$ ions, as also observed at $\mathrm{CeO}_{2}$ surfaces. ${ }^{32}$ These structures reproduce the experimental intensity observed at 560, 837, and 990 ppm, but not the distinct and intense signal at $680 \mathrm{ppm}$; the lack of agreement with the experimental spectrum can most easily be seen by simulating the ${ }^{17} \mathrm{O}$ NMR spectrum from the calculated parameters for each interfacial structure (Figure S5).

To identify the $680 \mathrm{ppm}$ signal, the $45^{\circ}$ interface was then calculated. Unlike the $0^{\circ}$ interface, at the $45^{\circ}$ interface every other layer is purely anionic for both structures (Figure 1c), so the interface could logically consist of a shared anionic layer. The stoichiometry of this layer, however, is not necessarily obvious: in a single supercell comprising 7 STO unit cells and $5 \mathrm{CeO}_{2}$ unit cells in the $c$ direction, an STO anion plane contains $14 \mathrm{O}^{2-}$ ions and $\mathrm{CeO}_{2}$ plane contains $20 \mathrm{O}^{2-}$ ions; the interfacial anion layer could therefore conceivably have any stoichiometry in this range.

Initial calculations were performed on a simple model of the $45^{\circ}$ interface (Figure S6). This model contains two interfaces: at the first, the anion layer is arranged according to the STO structure with $14 \mathrm{O}^{2-}$ ions (Figure $3 \mathrm{~b}$ ), while at the second, the anion layer arises from the $\mathrm{CeO}_{2}$ structure with $20 \mathrm{O}^{2-}$ ions (Figure $3 \mathrm{c}$ ). The structure was relaxed using DFT and the ${ }^{17} \mathrm{O}$ shifts calculated for each interface (STO- and $\mathrm{CeO}_{2}$-like, Figure 2c). There is some variation of the local oxygen environment in the adjacent layers, but beyond $4 \AA$ from the interface, the ${ }^{17} \mathrm{O}$ shifts match those of the bulk materials.

The calculated shifts for the interfacial oxygens (Figure 2c) are now clearly intermediate between those of $\mathrm{CeO}_{2}$ and STO; this is a consequence of the mixed coordination environment: a $\mathrm{Ce}^{4+}$ layer on one side and a $\mathrm{SrTiO}^{4+}$ layer on the other. The calculated shifts for the STO-like $14 \mathrm{O}^{2-}$ ion interface $(\sim 740-$ 780 ppm; see also Figure S5) are higher than for the $\mathrm{CeO}_{2}$-like interface; in the former interface, there are too few oxygen ions to fully coordinate all of the $\mathrm{Ce}^{4+}$ ions, so the undercoordinated cations withdraw more electron density from their adjacent oxygen anions, deshielding them and increasing the ${ }^{17} \mathrm{O}$ shift. For the $\mathrm{CeO}_{2}$-like $20 \mathrm{O}^{2-}$ ion interface, on the other hand, ${ }^{17} \mathrm{O}$ shifts are predicted in the range $660-700 \mathrm{ppm}$, which are consistent with the experimentally observed signal at $680 \mathrm{ppm}$ (see also Figure S5); these arise from approximately tetrahedrally coordinated oxygen ions with two adjacent $\mathrm{Ce}^{4+}$ ions, one $\mathrm{Ti}^{4+}$, and one $\mathrm{Sr}^{2+}$.

To gain further insight into the $45^{\circ}$ interface, the same random structure searching approach previously used for the $0^{\circ}$ interface $^{30}$ was applied. In this case, an intermediate initial model was chosen with $17 \mathrm{O}^{2-}$ ions per interface; the supercell was constructed so that the two interfaces are related by a mirror plane and are therefore equivalent. Low-energy structures were found by RSS using empirical interatomic potentials, and a representative structure was relaxed with DFT (Figures $3 \mathrm{~d}$ and $\mathrm{S} 7$ ). In this structure, there has been exchange of a $\mathrm{Ce}^{4+}$ and $\mathrm{a} \mathrm{Ti}^{4+}$ ion at the interface, which was a common feature in the RSS results and suggests that cation migration (mixing) can occur at this interface to lower the interfacial energy. The ${ }^{17} \mathrm{O}$ NMR shifts were then calculated (Figures $2 \mathrm{c}$ and S5); there is a wider range of shifts for the ions at the interface $(670-785 \mathrm{ppm})$, with environments that are similar to both the STO- and $\mathrm{CeO}_{2}$-like interfaces.

${ }^{17} \mathrm{O}$ is a quadrupolar nucleus $(I=5 / 2)$, therefore in principle the quadrupolar coupling to the local electric field gradient (as measured by the quadrupolar coupling constant, $C_{\mathrm{Q}}$ ) can provide further information on the oxygen environments. Bulk $\mathrm{CeO}_{2}$ has no ${ }^{17} \mathrm{O}$ quadrupolar coupling $\left(C_{\mathrm{Q}}=0\right)$ due to the 
tetrahedral oxygen environment and STO has a small $C_{\mathrm{Q}}$ of 1.0 $\mathrm{MHz} ;{ }^{52}$ the interface, on the other hand, may be expected to have more distorted environments. Figure S8 shows the calculated ${ }^{17} \mathrm{O} C_{\mathrm{Q}}$ constants for the two $45^{\circ}$ interface models: the calculated $\mathrm{C}_{\mathrm{Q}}$ constants are low $(<0.5 \mathrm{MHz})$ for the $\mathrm{CeO}_{2}$ regions, increasing somewhat toward the interfaces, while the STO slabs exhibit larger $C_{\mathrm{Q}}$ constants $(\sim 1 \mathrm{MHz})$, albeit also with a large spread. The only interface that induces markedly higher $C_{\mathrm{Q}}$ constants is the $\mathrm{CeO}_{2}$-like interface, up to $3 \mathrm{MHz}$ for certain oxygen ions in the adjacent $\mathrm{SrTiO}^{4+}$ layer; this reflects the large anisotropy induced by having an adjacent anion from the $\mathrm{CeO}_{2}$-like layer, rather than the otherwise cationic coordination. The lack of such environments in the RSS interface suggests that such high-energy environments are not realistic. However, even environments with quadrupolar coupling up to $C_{\mathrm{Q}}=3 \mathrm{MHz}$ would be hard to distinguish in the experimental spectrum on the basis of the second-order linewidth $(\sim 32 \mathrm{ppm})$ or shift $(\sim 20 \mathrm{ppm})$, since these are less than the experimental linewidth for the interfacial signal (115 ppm). MQMAS experiments could potentially identify such environments ${ }^{42}$ but would be too time consuming here due to the low SNR, and in a nutation experiment it would be challenging to differentiate the overlapping components with different quadrupolar coupling constants; therefore, in this case, further insight cannot be readily be gained from the quadrupolar coupling.

Of the models considered for the $45^{\circ}$ interface, the best agreement with the experimental ${ }^{17} \mathrm{O}$ NMR signal at $680 \mathrm{ppm}$ is for the $\mathrm{CeO}_{2}$-like interface; this may suggest an oxygen-rich stoichiometry closer to $20 \mathrm{O}^{2-}$ ions, which would require defects such as oxygen vacancies nearby to maintain charge neutrality. The STO-like $14 \mathrm{O}^{2-}$ interface is unlikely to be a major component since the calculated shifts are too high. The intermediate stoichiometry $17 \mathrm{O}^{2-}$ interface, however, predicts environments that are in reasonable agreement with experiment, and the structure is more realistic due to the RSS approach. A more thorough screening of the ${ }^{17} \mathrm{O}$ shifts of other structures derived by RSS may reveal that some structures have a closer match to experiment, but this is not the aim of the present study. In any case, the $680 \mathrm{ppm}$ signal can confidently be assigned to oxygen ions in the common anionic layer of the $45^{\circ}$ interface.

The question thus arises, although this spectrum is not quantitative due to the relatively short recycle delay and possible quadrupolar nutation effects, why does there appear to be a greater intensity for environments ascribed to the $45^{\circ}$ interface than for the $0^{\circ}$ interface, given that TEM indicates a three times greater proportion of the latter? Since environments that resonate around 560, 840, and $990 \mathrm{ppm}$ are also predicted for the $45^{\circ}$ interface, very little of the $0^{\circ}$ interface may actually be observed. As the ${ }^{17} \mathrm{O}$ enrichment was performed at a reasonably low temperature $\left(450{ }^{\circ} \mathrm{C}\right)$, this implies a greater oxide-ion conductivity for the $45^{\circ}$ interface. This motivated a more detailed NMR study of the ionic transport.

Oxide-Ion Conductivity. To investigate the relative oxideion conductivities of the $\mathrm{CeO}_{2}, \mathrm{STO}$, and $45^{\circ}$ interface, the ${ }^{17} \mathrm{O}$ enrichment was performed as a function of temperature (Figure 4); the same sample and NMR rotor were progressively enriched at 250,350 , and $450{ }^{\circ} \mathrm{C}$, without unpacking the sample, to allow direct comparison of the spectra. At the lower temperatures, there is $\sim 5 \times$ less enrichment than at $450{ }^{\circ} \mathrm{C}$, suggesting that there is insufficient

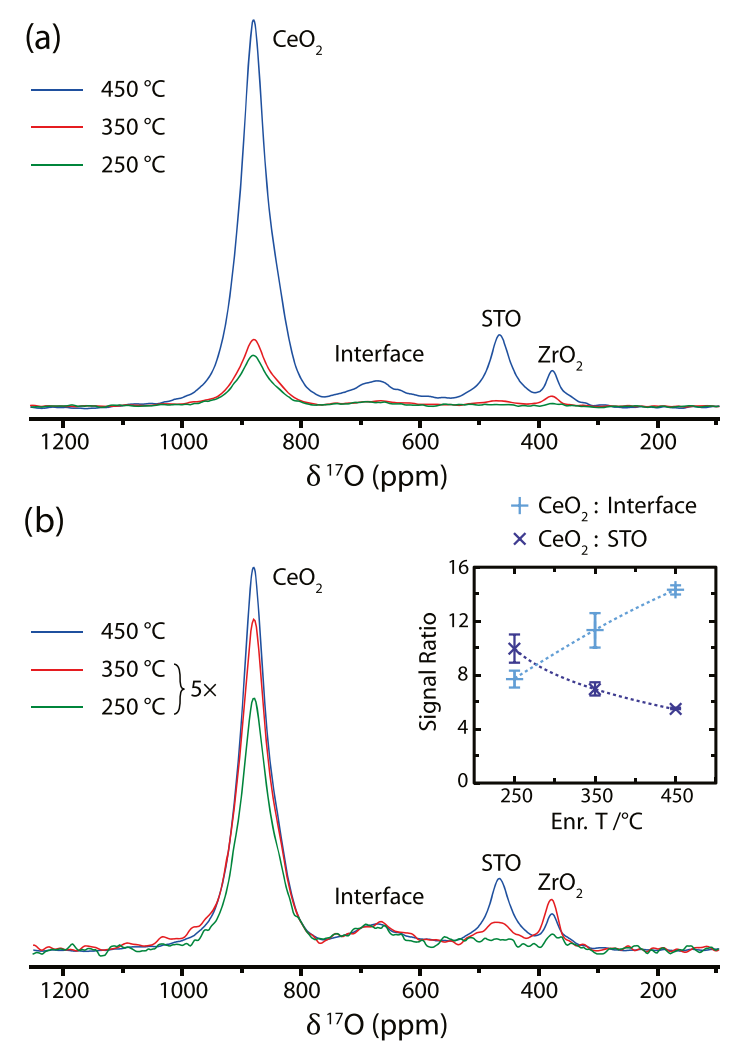

Figure 4. (a) ${ }^{17} \mathrm{O}$ NMR spectra of $\mathrm{CeO}_{2}-\mathrm{STO}$ lift-off films as a function of the ${ }^{17} \mathrm{O}_{2}$ enrichment temperature, recorded at $9.40 \mathrm{~T}$ and $50 \mathrm{kHz}$ MAS using a Hahn echo sequence, a $1 \mathrm{~s}$ recycle delay and between 80000 and 160000 scans (1-2 days). The spectra in (b) have been rescaled to give the same intensity of the interface signal. The inset shows the ratio of the integrated $\mathrm{CeO}_{2}$ intensity to the intensity of the interface and STO signals; the errors were estimated by fitting a peak to a region of noise.

diffusion of ${ }^{17} \mathrm{O}$ through the thickness of the film but rather a degree of surface selectivity (in agreement with previous results on $\mathrm{CeO}_{2}$ nanoparticles ${ }^{32}$ ). Although the intensity of all of the signals increases with increasing enrichment temperature, and the recycle delay is far from quantitative, the relative oxide-ion conductivities of the phases can nevertheless be inferred from the comparative intensities. This can be more easily seen by scaling the spectra so that the interface signal has the same intensity (Figure 4b); both the $\mathrm{CeO}_{2}$ and STO signals increase in intensity relative to the interface signal with increasing enrichment temperature, with a greater relative increase for the STO signal. Alternatively, by plotting the ratio of the $\mathrm{CeO}_{2}$ integrated intensity to those of the interface and STO signals (Figure $4 \mathrm{~b}$ inset), it can be seen that at higher enrichment temperatures the enrichment of the $\mathrm{CeO}_{2}$ increases relative to the interface and that of the STO increases relative to the $\mathrm{CeO}_{2}$. This implies that the oxide-ion conductivities are in the order: $\mathrm{STO}<\mathrm{CeO}_{2}<$ interface.

The greater mobility of the oxygen ions at the $45^{\circ}$ interface may also be probed by relaxometry measurements. Transverse $\left(T_{2}\right)$ decay, as measured by the change in intensity following a variable-length Hahn echo experiment, can be induced by the spins exchanging among different environments on a timescale comparable to the spread of frequencies that are sampled ${ }^{53,54}$ (see Supporting Information Note 2 for simulated exchangeinduced $T_{2}$ decay). Since the motion of the oxygen ions will be thermally activated, the $T_{2}$ will be temperature-dependent if 
the motional rate is comparable to the range of frequencies sampled. Figure 5 shows the integrated intensity of the $\mathrm{CeO}_{2}$

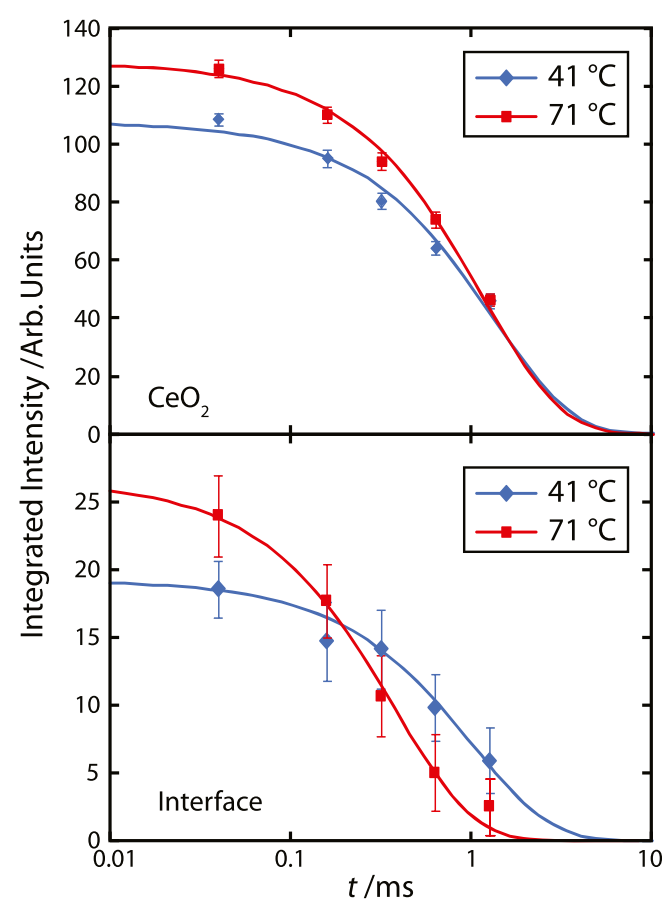

Figure 5. ${ }^{17} \mathrm{O} T_{2}$ decay curves for the $\mathrm{CeO}_{2}$ and interface signals measured at two different temperatures, for $\mathrm{CeO}_{2}-\mathrm{STO}$ lift-off films ${ }^{17} \mathrm{O}$-enriched at $350{ }^{\circ} \mathrm{C}$. The integrated intensity was measured as a function of the total echo length, $t$, in a Hahn echo experiment performed at $9.40 \mathrm{~T}$ and $50 \mathrm{kHz}$ MAS with a $0.1 \mathrm{~s}$ recycle delay.

and interface signals as a function of the echo length for two temperatures. The fitted $T_{2}$ of the bulk $\mathrm{CeO}_{2}$ signal changes little between the two temperatures (the initial intensity for the bulk signal is higher at the higher temperature due to slightly faster $T_{1}$ relaxation, see Figure S9), whereas the fitted $T_{2}$ for the interfacial signal is significantly shorter at the higher temperature, dropping from $1.0 \pm 0.3$ to $0.40 \pm 0.10 \mathrm{~ms}$ (Table 1). A $T_{2}$ constant that decreases at higher temperature

Table 1. Fitted $\mathrm{T}_{2}$ Decay Constants for the $\mathrm{CeO}_{2}$ and Interface Signals at Two Different Temperatures

\begin{tabular}{ccc} 
& \multicolumn{2}{c}{$T_{2}(\mathrm{~ms})$} \\
\cline { 2 - 3 }$T\left({ }^{\circ} \mathrm{C}\right)$ & $\mathrm{CeO}_{2}$ & interface \\
41 & $1.33 \pm 0.08$ & $1.0 \pm 0.3$ \\
71 & $1.23 \pm 0.06$ & $0.40 \pm 0.10$
\end{tabular}

suggests exchange in the slow-motion regime, i.e., slower than the range of sampled frequencies. Assuming that the exchange rate follows an Arrhenius temperature dependence, and that therefore so too does the $T_{2}$ decay, an activation energy of 0.30 $\pm 0.13 \mathrm{eV}$ can be estimated from the (albeit only two) temperature points. Unfortunately, the temperature limits of the low-volume fast MAS rotors prevent measurements of the $T_{2}$ decay at higher temperatures, so it is not possible to check whether the temperature dependence is indeed Arrhenius, but nevertheless the activation energy is consistent with previous NMR studies of oxygen motion. ${ }^{35,37,55}$ In any case, the temperature dependence of the $T_{2}$ relaxation for the ${ }^{17} \mathrm{O}$ ions at the $45^{\circ}$ interface provides strong evidence for oxygen motion around the $\mathrm{kHz}$ timescale and hence significant oxygen mobility, which would explain the greater enrichment of the $45^{\circ}$ interface, especially at lower temperatures. The higher maximum intensity of the interface peak at $71{ }^{\circ} \mathrm{C}$ than at 41 ${ }^{\circ} \mathrm{C}$, also observed in the $T_{1}$ measurement (Figure S7), suggests a distribution of correlation times for motion. A possible explanation is that there is a subset of environments at the interface undergoing faster exchange; these signals would coalesce at the higher temperature, increasing the peak intensity.

The high oxide-ion conductivity for the $45^{\circ}$ interface is consistent with its poorly defined stoichiometry (Figure 3 ): the anionic layer can feasibly support between 14 and $20 \mathrm{O}^{2-}$ ions per $\mathrm{STO}-\mathrm{CeO}_{2}$ supercell, whereas charge neutrality requires $17 \mathrm{O}^{2-}$ ions. Both sub- or superstoichiometric oxide ions can mediate ionic transport, and the stoichiometric interface can be considered to contain three vacancies.

The oxide-ion conductivity of 20 atom $\%$ Sm-doped $\mathrm{CeO}_{2}-$ STO VAN films was previously reported to be two orders of magnitude higher than Sm-doped $\mathrm{CeO}_{2}$ alone. ${ }^{18}$ Given the greater conductivity of the $45^{\circ}$ interface observed here by variable-temperature enrichment and NMR relaxometry studies, the $45^{\circ}$ interface may also be responsible for these previous results. For $25 \mathrm{~nm}$ pillars, assuming that the interface is $2.5 \AA$ wide, the total interface comprises $\sim 1 \%$ of the sample volume and the $45^{\circ}$ interface $\sim 0.25 \%$. The conductivity of the $45^{\circ}$ interface would therefore need to be four or five orders of magnitude higher than that of the bulk material to explain the observed conductivity increase. However, given the significant ${ }^{17} \mathrm{O}$ enrichment also observed for the $\mathrm{CeO}_{2}$ phase, it is likely that oxide-ion conductivity also involves the $\mathrm{CeO}_{2}$ layers near the interface, possibly via migration of vacancies from the interface into the bulk and/or residual disorder and tensile strain near these interfaces; while controversial, space charge effects may also play a role. ${ }^{56,57}$

Gd-Doped $\mathrm{CeO}_{2}-\mathrm{STO}$ Films. A second sample of the liftoff VAN films was prepared with 1 atom \% Gd-doped $\mathrm{CeO}_{2}$ nanopillars in an STO matrix. Gd doping increases the oxideion conductivity of $\mathrm{CeO}_{2}$ by introducing oxygen vacancies, and Gd-doped $\mathrm{CeO}_{2}$ is a common electrolyte in solid oxide fuel cells, ${ }^{58}$ although typically with higher Gd concentrations of at least $10 \%$. A further effect of $\mathrm{Gd}$ doping in $\mathrm{CeO}_{2}$ is to reduce the ${ }^{17} \mathrm{O} T_{1}$ relaxation constant due to paramagnetic relaxation enhancement (PRE). To explore this effect, $T_{1}$ measurements were made for model bulk samples, the $T_{1}$ values dropping from $\sim 550 \mathrm{~s}$ in pure $\mathrm{CeO}_{2}$ to $0.3 \mathrm{~s}$ for 1 atom $\% \mathrm{Gd}-\mathrm{CeO}_{2}$ (Figure S2). Thus, greater signal to noise could be achieved per unit time when measuring the Gd-doped thin films, and these experiments were performed with four $0.5 \mathrm{~cm}^{2}$ films, instead of eighteen as for the undoped films. Furthermore, Gd doping affords PRE without introducing additional signals to the already crowded ${ }^{17} \mathrm{O}$ NMR spectrum of the nanopillars because the environments directly adjacent to the Gd dopants relax too quickly to be observed (c.f. Sm- and Eu-doped $\mathrm{CeO}_{2}{ }^{35}$ ).

Figure 6 a shows the ${ }^{17} \mathrm{O}$ NMR spectrum of the Gd-doped $\mathrm{CeO}_{2}-\mathrm{STO}$ nanopillars, enriched at $450{ }^{\circ} \mathrm{C}$ and recorded with a $0.1 \mathrm{~s}$ recycle delay. The spectrum is similar to the undoped films, but the $\mathrm{CeO}_{2}$ signal is broader due to hyperfine coupling with the $\mathrm{Gd}$ dopants, so that the $\mathrm{CeO}_{2}$-like interfacial resonances can no longer be resolved. The sharper component of the $\mathrm{CeO}_{2}$ signal, corresponding now to environments that are far from both the interface and any Gd dopants, is 
(a)

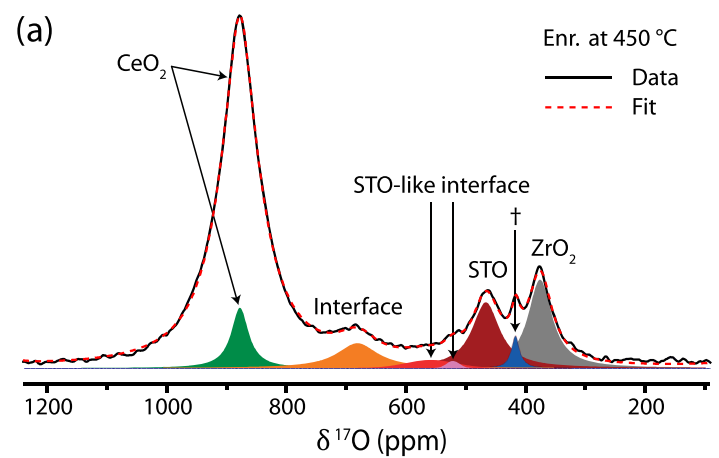

(b)
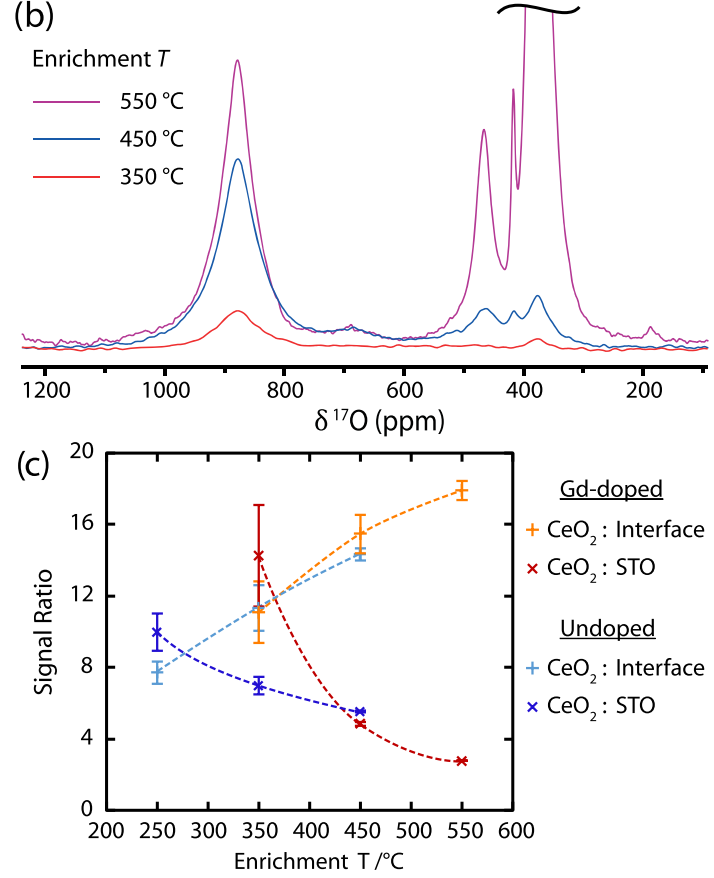

(d)

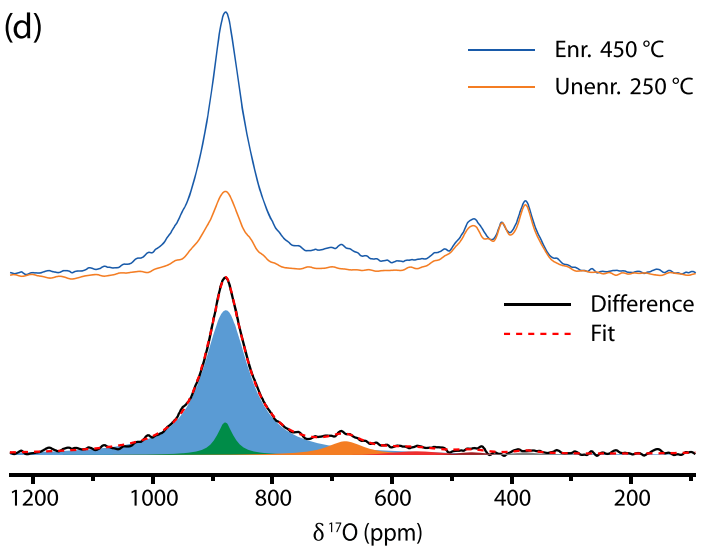

Figure 6. ${ }^{17} \mathrm{O}$ NMR spectra of $1 \%$ Gd-doped $\mathrm{CeO}_{2}-\mathrm{STO}$ lift-off films, recorded at $9.40 \mathrm{~T}$ and $50 \mathrm{kHz}$ MAS using a Hahn echo sequence, a $0.1 \mathrm{~s}$ recycle delay and between 800,000 and 1,660,000 scans (1-2 days). (a) Deconvolution of the sample enriched at 450 ${ }^{\circ} \mathrm{C}$; the signal marked with $\mathrm{a} \dagger$ is discussed in the text. (b) Comparison of the same sample enriched at different temperatures. (c) The ratios of the deconvoluted integrated intensities for the $\mathrm{CeO}_{2}$, STO and interface signals as a function of enrichment temperature. The errors are estimated by fitting a peak to a region of noise. (d) The spectrum of the sample enriched at $450{ }^{\circ} \mathrm{C}$ after unenriching in air at $250^{\circ} \mathrm{C}$, as well as a deconvolution of the difference spectrum.

accordingly less intense. An additional slightly sharper component of the STO-like interface can be discerned at
$522 \mathrm{ppm}$, and the $45^{\circ}$ interface signal is again centered at 680 $\mathrm{ppm}$. The sharp signal at $417 \mathrm{ppm}$ (labeled with a $\dagger$ ) is tentatively ascribed to a different local environment in the $\mathrm{ZrO}_{2}$ rotor caused by dopants/impurities and was also observed for the second batch of the undoped $\mathrm{CeO}_{2}-\mathrm{STO}$ nanopillars (Figure S4).

A comparison of the ${ }^{17} \mathrm{O}$ NMR spectra following enrichment of the same sample between 350 and $550{ }^{\circ} \mathrm{C}$ (Figure 6b) shows an approximately five-fold increase in intensity for both the $\mathrm{CeO}_{2}$ and interface signals between 350 and $450{ }^{\circ} \mathrm{C}$, as was also observed for the undoped films. But while the intensity of the $\mathrm{CeO}_{2}$ signal further increases after enrichment at $550{ }^{\circ} \mathrm{C}$, there is little change in the interface intensity; this is again evidence of greater oxygen mobility at the $45^{\circ}$ interface, since $450{ }^{\circ} \mathrm{C}$ is sufficient for almost complete enrichment of the interface, but not of the bulk $\mathrm{CeO}_{2}$. This can also be seen by plotting the relative signal ratios as a function of the enrichment temperature (Figure 6c); again the $\mathrm{CeO}_{2}$ :interface ratio increases with increasing enrichment temperature, while the $\mathrm{CeO}_{2}$ :STO ratio decreases, implying that the relative conductivities are in the order: interface $>\mathrm{CeO}_{2}>\mathrm{STO}$. Furthermore, the ratios are comparable to the undoped case, suggesting that $1 \%$ of $\mathrm{Gd}$ doping has not had a significant effect on the relative conductivities, except perhaps that the oxygen mobility is greater in the $\mathrm{CeO}_{2}$ relative to the $\mathrm{STO}$ at $350{ }^{\circ} \mathrm{C}$, as would be expected, although there may be a large error associated with this ratio due to the broad low-intensity STO signal.

An additional experiment was also performed in which the sample was unenriched by heating in air at $250{ }^{\circ} \mathrm{C}$ after having been enriched with ${ }^{17} \mathrm{O}$ at $450{ }^{\circ} \mathrm{C}$, to induce back-exchange with ${ }^{16} \mathrm{O}$ in the air for the more labile ${ }^{17} \mathrm{O}$-enriched environments. The ${ }^{17} \mathrm{O}$ NMR spectrum (Figure 6d) exhibits a decrease in the signals of predominantly the $\mathrm{CeO}_{2}$ and interface environments, as shown by the difference spectrum. This indicates that the oxide-ion conductivity of STO is only sufficiently high at higher temperatures to allow significant exchange of ${ }^{16 / 17} \mathrm{O}$, corroborating the aforementioned higher ionic conductivity of bulk $\mathrm{CeO}_{2}$ and the interfaces, relative to STO.

\section{CONCLUSIONS}

Distinct ${ }^{17} \mathrm{O}$ NMR signals arising from a single atomic layer at each internal solid-solid interface were observed for the first time, for the case of a thin-film oxide heterostructure formed from a $\mathrm{CeO}_{2}-\mathrm{STO}$ vertically aligned nanocomposite (VAN). This was made possible by the development of a lift-off and enrichment procedure to minimize sample loss and maximize signal to noise. The mass of thin films is already low, but as $2 \mathrm{D}$ entities the mass of the $\mathrm{CeO}_{2}-\mathrm{STO}$ interface is even less ( $0.01 \mathrm{mg}$ for eighteen $0.5 \mathrm{~cm}^{2}$ films), which represents an extreme sensitivity challenge for NMR; despite this, it was still possible to obtain high-quality ${ }^{17} \mathrm{O}$ NMR spectra in less than a day. Doping with $\mathrm{Gd}^{3+}$ reduces the ${ }^{17} \mathrm{O} T_{1}$ constants by paramagnetic relaxation enhancement, increasing the signal-tonoise ratio per unit time and allowing similar quality spectra to be obtained from fewer films.

DFT calculations then permitted the major interfacial signal to be assigned to the $\mathrm{CeO}_{2}$ (100)/STO (110) " $45^{\circ}$ " interface, a potential structure for which was determined from random structure searching, consisting of an anionic layer sandwiched between $\mathrm{Ce}^{4+}$ and $\mathrm{SrTiO}^{4+}$ layers from the $\mathrm{CeO}_{2}$ and $\mathrm{STO}$ phases, with a stoichiometry intermediate between the two 
bulk structures. The qualitatively greater oxygen mobility of this interface was demonstrated by performing ${ }^{17} \mathrm{O}$ enrichment as a function of temperature, as well as by ${ }^{17} \mathrm{O} N M R$ relaxometry, and we propose that this specific interface makes a significant contribution to the increased oxide-ion conductivity of the $\mathrm{CeO}_{2}-\mathrm{STO}$ VAN films. ${ }^{18}$ Enhanced oxygen mobility for this frustrated interface was ascribed to the disorder and range of possible oxygen stoichiometries, which can mediate oxygen transport. By tailoring film growth to increase the proportion of the $45^{\circ}$ interface, it may be possible to further improve the oxygen conductivity.

In general, new oxide heterostructures that contain shared anionic layers may have similarly enhanced oxide-ion conductivities due to the disorder and variable stoichiometry inherently imposed at the interface between two incompatible crystal structures. This is an important design principle to exploit. Furthermore, the methodology presented here will allow the atomic structure of new oxide heterostructure interfaces to be investigated, uncovering further structureproperty relationships, which are key to optimizing device performance.

\section{METHODS}

Film Synthesis, Lift-off, and Enrichment. A schematic for the film growth and lift-off procedure is shown in Figure S1. All thin films were grown by pulsed laser deposition (PLD) with a $\mathrm{KrF}$ excimer laser $(\lambda=248 \mathrm{~nm})$ on STO $(001)$ substrates $(1 \mathrm{~cm} \times 0.5 \mathrm{~cm})$, to a thickness of around $1 \mu \mathrm{m}$ as measured by a Veeco Dektak $6 \mathrm{M}$ stylus profilometer. Polycrystalline PLD targets were prepared via solid-state synthesis: the as-received precursors were hand-ground before sintering in air at $1350{ }^{\circ} \mathrm{C}$ for $48 \mathrm{~h}$, with an intermediate grinding and pelletizing step. $\mathrm{Sr}_{3} \mathrm{Al}_{2} \mathrm{O}_{6}$ targets were prepared from a stoichiometric mixture of $\mathrm{SrO}$ (Sigma-Aldrich, 99.9\%) and $\mathrm{Al}_{2} \mathrm{O}_{3}$ (Alfa Aesar, 99.97\%) powders. $\mathrm{CeO}_{2} / \mathrm{STO}$ and $\mathrm{Gd}_{0.01} \mathrm{Ce}_{0.99} \mathrm{O}_{1.995} /$ STO targets were prepared from mixtures of $\mathrm{CeO}_{2}$ (Alfa Aesar, 99.9\%), $\mathrm{SrTiO}_{3}$ (Sigma-Aldrich, 99.9\%), and $\mathrm{Gd}_{2} \mathrm{O}_{3}$ (Sigma-Aldrich, 99.9\%) as required; the targets comprised a $1: 1$ molar ratio of the total metal content in the (doped) $\mathrm{CeO}_{2}$ to the $\mathrm{STO}$.

Before deposition of the target films, a $\mathrm{Sr}_{3} \mathrm{Al}_{2} \mathrm{O}_{6}$ buffer layer was grown on the $\mathrm{SrTiO}_{3}(001)$ substrate at a substrate temperature $T_{\mathrm{g}}=$ $700{ }^{\circ} \mathrm{C}$ with $p_{\mathrm{O}_{2}}=1 \times 10^{-6} \mathrm{mbar}$, while using a $1.25 \mathrm{~J} \cdot \mathrm{cm}^{-2}$ laser fluence and a repetition rate of $1 \mathrm{~Hz}$ for $10 \mathrm{~min}$. The target nanocomposite films were then grown in situ at $T_{\mathrm{g}}=750{ }^{\circ} \mathrm{C}$ and $p_{\mathrm{O}_{2}}$ $=0.2 \mathrm{mbar}$, using a $1.5 \mathrm{~J} \cdot \mathrm{cm}^{-2}$ laser fluence and a repetition rate of 5 $\mathrm{Hz}$ for $2 \mathrm{~h}$. After deposition, all films were postannealed at $650{ }^{\circ} \mathrm{C}$ for $1 \mathrm{~h}$ under $p_{\mathrm{O}_{2}}=0.8$ bar to ensure equilibrium oxygen stoichiometry.

Poly(methyl methacrylate) (PMMA, Alfa Aesar, $M_{\mathrm{w}}=950 \mathrm{~kg}$. $\mathrm{mol}^{-1}$ ) was dissolved in anisole (4 wt \%, Sigma-Aldrich, 99.7\%) and spin-coated (2000 RPM, $30 \mathrm{~s}$ ) onto the thin film with the substrate, then naturally dried for $12 \mathrm{~h}$ to obtain a PMMA layer with a thickness of $\sim 300 \mathrm{~nm}$. A polyethylene (PET) sheet was then pressed onto the film on the PMMA side by hand. The thin film, together with the PMMA layer and PET sheet, was immersed in deionized water to dissolve the $\mathrm{Sr}_{3} \mathrm{Al}_{2} \mathrm{O}_{6}$ buffer layer and remove the substrate. After etching in water, the PET support was removed by dissolving the PMMA layer in chloroform and the chloroform syringed off. Finally, the thin film was dispersed in acetone and added to a $1.3 \mathrm{~mm}$ outer diameter $\mathrm{ZrO}_{2}$ rotor (open at both ends), the lower half of which had been packed with $\mathrm{KBr}$. The acetone filtered through the $\mathrm{KBr}$ and/or evaporated, leaving the thin film in the rotor. The top half of the rotor was then also filled with $\mathrm{KBr}$ so that the sample was center-packed. The packed rotor (without caps) was placed in a $\sim 20 \mathrm{~cm}^{3}$ quartz tube, which was filled with $\sim 50$ mbar of ${ }^{17} \mathrm{O}$-enriched $\mathrm{O}_{2}$ gas (NUKEM Isotopes, 70 atom \%), while the tube was immersed in liquid nitrogen (resulting in $\sim 0.6 \mathrm{mmol}$ of ${ }^{17} \mathrm{O}_{2}$ ), before heating the sealed tube at the desired enrichment temperature $\left(250{ }^{\circ} \mathrm{C}-550^{\circ} \mathrm{C}\right)$ overnight. Note that in all cases the enrichment temperature is lower than the postannealing treatment temperature used to prepare the films $\left(650{ }^{\circ} \mathrm{C}\right)$. For the undoped ${ }^{17} \mathrm{O}$-enriched $\mathrm{CeO}_{2}-\mathrm{STO}$ films, eighteen $0.5 \mathrm{~cm}^{2}$ films were packed in the single rotor, and for the Gddoped $\mathrm{CeO}_{2}-\mathrm{STO}$ films, four $0.5 \mathrm{~cm}^{2}$ films were packed into the rotor. The samples were handled in air but stored in an Ar glovebox. For progressive enrichments of the same sample, the rotor caps were removed, and the enrichment procedure was repeated with the same rotor. Unenrichment was performed in the same way, but with the quartz tube left open to air during overnight heating.

Solid-State NMR. The NMR spectra were recorded on a $9.40 \mathrm{~T}$ Bruker Avance spectrometer using a Bruker $1.3 \mathrm{~mm} \mathrm{HX}$ probe, 50 $\mathrm{kHz}$ MAS frequency, and a Hahn echo pulse sequence $(\pi / 2-$ $\tau-\pi-\tau$-acquire), with recycle delays of $0.1-1 \mathrm{~s}$ as specified in the figure captions. Variable-temperature NMR experiments were performed by application of heated nitrogen gas and the sample temperature was determined from an ex situ calibration using the temperature-dependent ${ }^{207} \mathrm{~Pb}$ shift of $\mathrm{Pb}\left(\mathrm{NO}_{3}\right)_{2} \cdot{ }^{59}$ The ${ }^{17} \mathrm{O}$ spectra were referenced to $\mathrm{H}_{2} \mathrm{O}$ at $0 \mathrm{ppm}$ and deconvoluted using the dmfit program. ${ }^{60} T_{1}$ and $T_{2}$ relaxation constants, and the errors in these values, were determined by total least-squares refinement of saturation recovery and variable-length Hahn echo data using IGOR Pro.

DFT Calculations. Density functional theory (DFT) calculations were performed using the plane-wave pseudopotential code CASTEP $^{61}$ and the general gradient approximation-based PBEsol exchange correlation functional. ${ }^{62}$ The valence states of $2 \mathrm{~s} 2 \mathrm{p}$ for $\mathrm{O}, 3 \mathrm{~s} 3 \mathrm{p} 3 \mathrm{~d} 4 \mathrm{~s}$ for $\mathrm{Ti}, 4 \mathrm{~s} 4 \mathrm{p} 5 \mathrm{~s}$ for $\mathrm{Sr}$, and $4 \mathrm{f} 5 \mathrm{~s} 5 \mathrm{p} 5 \mathrm{~d} 6 \mathrm{~s}$ for Ce were treated using on-the-fly generated (OTFG) core-corrected ultrasoft pseudopotentials. Due to the large system size, a softer set of pseudopotentials from the QC5 library were used that require lower cutoff energies than the standard CASTEP pseudopotentials from the C18 library. The convergence was checked for the QC5 potential and a plane-wave cutoff energy of $350 \mathrm{eV}$ was found to be sufficient (Figure S10). For one of the interface models, the shieldings calculated with the softer pseudopotentials were then compared to shieldings calculated using the default pseudopotentials with a converged cutoff energy of $700 \mathrm{eV}$ (Figure S11); the two pseudopotentials were found to give almost identical results for the STO region and an error of up to $15 \mathrm{ppm}$ for the $\mathrm{CeO}_{2}$ region (Figure $\mathrm{S} 12)$, which is significantly less than the experimental linewidth $(\sim 115 \mathrm{ppm})$. Generation settings for both pseudopotential sets are tabulated in Tables S2 and S3. Reciprocal space was sampled with a 1 $\times 4 \times 1$ Monkhorst-Pack grid for the $0^{\circ}$ interface and a $1 \times 6 \times 1$ grid for the $45^{\circ}$ interface (described below). The GIPAW method ${ }^{63,64}$ integrated with CASTEP was used for calculating the NMR shielding of ${ }^{17} \mathrm{O}$ ions. The shielding was converted to the chemical shift by fitting to the experimental values of STO and $\mathrm{CeO}_{2}$ (465 and 877 ppm, respectively), using the regression $\delta=-0.5914 \sigma+298.15$; the resulting shifts for the interface are therefore effectively interpolated between those of the pure materials, affording cancellation of any systematic errors in the shieldings. The Atomic Simulation Environment (ASE) $)^{65}$ was used to prepare input structures and search seeds. DFT calculations were managed and automated using the AiiDA framework. ${ }^{66}$ Structures were visualized using the VESTA software package. $^{67}$

Interface Models. The structures for the $0^{\circ}$ interface were taken from $\mathrm{Zhu}$ et al., ${ }^{30}$ and the same interface structure searching procedures described therein were used here for the $45^{\circ}$ interface. For the $0^{\circ}$ interface, a slab model was used with an overall thickness of $\sim 14 \AA$, comprising the STO and $\mathrm{CeO}_{2}$ structures with the interface in the middle, surrounded by vacuum; by calculating a thicker slab, the $14 \AA$ slab was shown to be sufficient to converge the NMR parameters for the interface (Figure S13). The outer layers are, however, affected by the external surface and for this reason the shifts of the bulk materials are not reproduced; for instance, the overestimation of the $\mathrm{CeO}_{2}{ }^{17} \mathrm{O}$ shift away from the interface is consistent with the higher calculated and experimental ${ }^{17} \mathrm{O}$ shifts for $\mathrm{CeO}_{2}$ surfaces. ${ }^{32}$ For the $45^{\circ}$ interface, a periodic model was used with two interfaces, as described in the text. The random structure searching was performed by randomizing atomic positions in the first 
layers on either side of the interface, subject to species-wise minimal separation constraints, followed by relaxing the ionic positions with fixed cell parameters along the directions parallel to the interface plane, using interatomic potentials as described in Zhu et al. ${ }^{30}$ The simulation cells for the $45^{\circ}$ interface contained two equivalent interfaces that are mirror images of each other. The procedure was repeated until the lowest-energy structures had been repetitively found. A total of 8966 candidate structures were generated and evaluated. The lowest-energy structure was further relaxed by DFT and used to compute the NMR shifts.

\section{ASSOCIATED CONTENT}

\section{(s) Supporting Information}

The Supporting Information is available free of charge at https://pubs.acs.org/doi/10.1021/acs.chemmater.0c02698.

Details on the methodology, additional ${ }^{17} \mathrm{O}$ NMR spectra, ${ }^{17} \mathrm{O} T_{1}$ relaxation analysis; DFT structures and additional results; DFT convergence testing; analysis of the orientations of the interfaces; calculated $T_{2}$ relaxation under two-site exchange (PDF)

Spreadsheet of calculated ${ }^{17} \mathrm{O}$ parameters for different interfacial structures (XLSX)

\section{AUTHOR INFORMATION}

\section{Corresponding Author}

Clare P. Grey - Department of Chemistry, University of Cambridge, Cambridge CB2 1EW, United Kingdom; 이 orcid.org/0000-0001-5572-192X; Email: cpg27@ cam.ac.uk

\section{Authors}

Michael A. Hope - Department of Chemistry, University of Cambridge, Cambridge CB2 1EW, United Kingdom; (1) orcid.org/0000-0002-4742-9336

Bowen Zhang - Department of Materials Science and Metallurgy, University of Cambridge, Cambridge CB3 OFS, United Kingdom

Bonan Zhu - Department of Materials Science and Metallurgy, University of Cambridge, Cambridge CB3 OFS, United Kingdom; orcid.org/0000-0001-5601-6130

David M. Halat - Department of Chemistry, University of Cambridge, Cambridge CB2 1EW, United Kingdom; (ㄱ) orcid.org/0000-0002-0919-1689

Judith L. MacManus-Driscoll - Department of Materials Science and Metallurgy, University of Cambridge, Cambridge CB3 OFS, United Kingdom

Complete contact information is available at: https://pubs.acs.org/10.1021/acs.chemmater.0c02698

\section{Notes}

The authors declare no competing financial interest. The raw data for the NMR and DFT calculations can be found at DOI: $10.24435 /$ materialscloud:4v-04.

\section{ACKNOWLEDGMENTS}

M.A.H. is grateful for funding by an Oppenheimer studentship. B. Zhang and B. Zhu would like to thank the China Scholarship Council and the Cambridge Commonwealth, European and International Trust. D.M.H. acknowledges support from NECCES, an Energy Frontier Research Center funded by the U.S. Department of Energy, Office of Science, Office of Basic Energy Sciences under Award No. DESC0012583. C.P.G. and J.L.M-D. would like to thank the
Centre for Advanced Materials for Integrated Energy Systems under EP/P007767/1. J.L.M-D. would like to thank the ERCPOC grant 779444, Portapower and the Royal Academy of Engineering Grant, CIET1819_24. The calculations were performed on the CSD3 Supercomputer of the University of Cambridge (www.hpc.cam.ac.uk).

\section{REFERENCES}

(1) Ohtomo, A.; Hwang, H. Y. A High-Mobility Electron Gas at the $\mathrm{LaAlO}_{3} / \mathrm{SrTiO}_{3}$ Heterointerface. Nature 2004, 427, 423-426.

(2) Hwang, H. Y.; Iwasa, Y.; Kawasaki, M.; Keimer, B.; Nagaosa, N.; Tokura, Y. Emergent Phenomena at Oxide Interfaces. Nat. Mater. 2012, 11, 103-113.

(3) Tokura, Y.; Hwang, H. Y. Complex Oxides on Fire. Nat. Mater. 2008, 7, 694-695.

(4) MacManus-Driscoll, J. L. Self-Assembled Heteroepitaxial Oxide Nanocomposite Thin Film Structures: Designing Interface-Induced Functionality in Electronic Materials. Adv. Funct. Mater. 2010, 20, 2035-2045.

(5) Choi, E.-M.; Di Bernardo, A.; Zhu, B.; Lu, P.; Alpern, H.; Zhang, K. H. L.; Shapira, T.; Feighan, J.; Sun, X.; Robinson, J.; et al. 3D Strain-Induced Superconductivity in $\mathrm{La}_{2} \mathrm{CuO}_{4+\delta}$ Using a Simple Vertically Aligned Nanocomposite Approach. Sci. Adv. 2019, 5, No. eaav5532.

(6) MacManus-Driscoll, J. L.; Foltyn, S. R.; Jia, Q. X.; Wang, H.; Serquis, A.; Civale, L.; Maiorov, B.; Hawley, M. E.; Maley, M. P.; Peterson, D. E. Strongly Enhanced Current Densities in Superconducting Coated Conductors of $\mathrm{YBa}_{2} \mathrm{Cu}_{3} \mathrm{O}_{7-x}+\mathrm{BaZrO}_{3}$. Nat. Mater. 2004, 3, 439-443.

(7) Gutiérrez, J.; Llordés, A.; Gázquez, J.; Gibert, M.; Romà, N.; Ricart, S.; Pomar, A.; Sandiumenge, F.; Mestres, N.; Puig, T.; et al. Strong Isotropic Flux Pinning in Solution-Derived $\mathrm{YBa}_{2} \mathrm{Cu}_{3} \mathrm{O}_{7-x}$ Nanocomposite Superconductor Films. Nat. Mater. 2007, 6, 367373.

(8) Llordés, A.; Palau, A.; Gázquez, J.; Coll, M.; Vlad, R.; Pomar, A.; Arbiol, J.; Guzmán, R.; Ye, S.; Rouco, V.; et al. Nanoscale StrainInduced Pair Suppression as a Vortex-Pinning Mechanism in HighTemperature Superconductors. Nat. Mater. 2012, 11, 329-336.

(9) Choi, E.-M.; Weal, E.; Bi, Z.; Wang, H.; Kursumovic, A.; Fix, T.; Blamire, M. G.; MacManus-Driscoll, J. L. Strong Room Temperature Exchange Bias in Self-Assembled $\mathrm{BiFeO}_{3}-\mathrm{Fe}_{3} \mathrm{O}_{4}$ Nanocomposite Heteroepitaxial Films. Appl. Phys. Lett. 2013, 102, No. 012905.

(10) Fix, T.; Choi, E.-M.; Robinson, J. W. A.; Lee, S. B.; Chen, A.; Prasad, B.; Wang, H.; Blamire, M. G.; MacManus-Driscoll, J. L. Electric-Field Control of Ferromagnetism in a Nanocomposite via a ZnO Phase. Nano Lett. 2013, 13, 5886-5890.

(11) Khatkhatay, F.; Chen, A.; Lee, J. H.; Zhang, W.; Abdel-Raziq, H.; Wang, H. Ferroelectric Properties of Vertically Aligned Nanostructured $\mathrm{BaTiO}_{3}-\mathrm{CeO}_{2}$ Thin Films and Their Integration on Silicon. ACS Appl. Mater. Interfaces 2013, 5, 12541-12547.

(12) Harrington, S. A.; Zhai, J.; Denev, S.; Gopalan, V.; Wang, H.; Bi, Z.; Redfern, S. A. T.; Baek, S.-H.; Bark, C. W.; Eom, C.-B.; et al. Thick Lead-Free Ferroelectric Films with High Curie Temperatures through Nanocomposite-Induced Strain. Nat. Nanotechnol. 2011, 6, 491-495.

(13) Zheng, $\mathrm{H}$.; et al. Multiferroic $\mathrm{BaTiO}_{3}-\mathrm{CoFe}_{2} \mathrm{O}_{4}$ Nanostructures. Science 2004, 303, 661-663.

(14) Chen, A.; Bi, Z.; Tsai, C.-F.; Lee, J.; Su, Q.; Zhang, X.; Jia, Q.; MacManus-Driscoll, J. L.; Wang, H. Tunable Low-Field Magnetoresistance in $\left(\mathrm{La}_{0.7} \mathrm{Sr}_{0.3} \mathrm{MnO}_{3}\right)_{0.5}:(\mathrm{ZnO})_{0.5}$ Self-Assembled Vertically Aligned Nanocomposite Thin Films. Adv. Funct. Mater. 2011, 21, $2423-2429$.

(15) Zhang, W.; Chen, A.; Khatkhatay, F.; Tsai, C.-F.; Su, Q.; Jiao, L.; Zhang, X.; Wang, H. Integration of Self-Assembled Vertically Aligned Nanocomposite $\left(\mathrm{La}_{0.7} \mathrm{Sr}_{0.3} \mathrm{MnO}_{3}\right)_{1-x}:(\mathrm{ZnO})_{x}$ Thin Films on Silicon Substrates. ACS Appl. Mater. Interfaces 2013, 5, 3995-3999.

(16) Cho, S.; Yun, C.; Tappertzhofen, S.; Kursumovic, A.; Lee, S.; Lu, P.; Jia, Q.; Fan, M.; Jian, J.; Wang, H.; et al. Self-Assembled Oxide 
Films with Tailored Nanoscale Ionic and Electronic Channels for Controlled Resistive Switching. Nat. Commun. 2016, 7, No. 12373.

(17) Lee, S.; Zhang, W.; Khatkhatay, F.; Wang, H.; Jia, Q.; MacManus-Driscoll, J. L. Ionic Conductivity Increased by Two Orders of Magnitude in Micrometer-Thick Vertical Yttria-Stabilized $\mathrm{ZrO}_{2}$ Nanocomposite Films. Nano Lett. 2015, 15, 7362-7369.

(18) Yang, S. M.; Lee, S.; Jian, J.; Zhang, W.; Lu, P.; Jia, Q.; Wang, H.; Won Noh, T.; Kalinin, S. V.; MacManus-Driscoll, J. L. Strongly Enhanced Oxygen Ion Transport through Samarium-Doped $\mathrm{CeO}_{2}$ Nanopillars in Nanocomposite Films. Nat. Commun. 2015, 6, No. 8588.

(19) Chen, A.; Su, Q.; Han, H.; Enriquez, E.; Jia, Q. Metal Oxide Nanocomposites: A Perspective from Strain, Defect, and Interface. Adv. Mater. 2019, 31, No. 1803241.

(20) Yadav, A. K.; Nelson, C. T.; Hsu, S. L.; Hong, Z.; Clarkson, J. D.; Schlepütz, C. M.; Damodaran, A. R.; Shafer, P.; Arenholz, E.; Dedon, L. R.; et al. Observation of Polar Vortices in Oxide Superlattices. Nature 2016, 530, 198-201.

(21) Yun, H.; Ganguly, K.; Postiglione, W.; Jalan, B.; Leighton, C.; Mkhoyan, K. A.; Jeong, J. S. Microstructure Characterization of $\mathrm{BaSnO}_{3}$ Thin Films on $\mathrm{LaAlO}_{3}$ and $\mathrm{PrScO}_{3}$ Substrates from Transmission Electron Microscopy. Sci. Rep. 2018, 8, No. 10245.

(22) Prencipe, I.; Dellasega, D.; Zani, A.; Rizzo, D.; Passoni, M. Energy Dispersive X-Ray Spectroscopy for Nanostructured Thin Film Density Evaluation. Sci. Technol. Adv. Mater. 2015, 16, No. 025007.

(23) Islam, M. R.; Zubair, M. A.; Bashar, M. S.; Rashid, A. K. M. B. $\mathrm{Bi}_{0.9} \mathrm{Ho}_{0.1} \mathrm{FeO}_{3} / \mathrm{TiO}_{2}$ Composite Thin Films: Synthesis and Study of Optical, Electrical and Magnetic Properties. Sci. Rep. 2019, 9, No. 5205.

(24) Lee, S.; Zhang, W.; Khatkhatay, F.; Jia, Q.; Wang, H.; MacManus-Driscoll, J. L. Strain Tuning and Strong Enhancement of Ionic Conductivity in $\mathrm{SrZrO}_{3}-\mathrm{RE}_{2} \mathrm{O}_{3}(\mathrm{RE}=\mathrm{Sm}, \mathrm{Eu}, \mathrm{Gd}, \mathrm{Dy}$, and $\mathrm{Er})$ Nanocomposite Films. Adv. Funct. Mater. 2015, 25, 4328-4333.

(25) Stambouli, A. B.; Traversa, E. Solid Oxide Fuel Cells (SOFCs): A Review of an Environmentally Clean and Efficient Source of Energy. Renew. Sust. Energ. Rev. 2002, 6, 433-455.

(26) Sim, L. T.; Lee, C. K.; West, A. R. High Oxide Ion Conductivity in $\mathrm{Bi}_{2} \mathrm{MoO}_{6}$ Oxidation Catalyst. J. Mater. Chem. 2002, 12, 17-19.

(27) Lu, N.; Zhang, P.; Zhang, Q.; Qiao, R.; He, Q.; Li, H.-B.; Wang, Y.; Guo, J.; Zhang, D.; Duan, Z.; et al. Electric-Field Control of TriState Phase Transformation with a Selective Dual-Ion Switch. Nature 2017, 546, 124-128.

(28) Wołcyrz, M.; Kepinski, L. Rietveld Refinement of the Structure of $\mathrm{CeOCl}$ Formed in $\mathrm{Pd} / \mathrm{CeO}_{2}$ Catalyst: Notes on the Existence of a Stabilized Tetragonal Phase of $\mathrm{La}_{2} \mathrm{O}_{3}$ in La-Pd-O System. J. Solid State Chem. 1992, 99, 409-413.

(29) Nelmes, R. J.; Meyer, G. M.; Hutton, J. High-Resolution (Direct Space) Studies of Anharmonic Motion Associated with the Structural Phase Transition in $\mathrm{SrTiO}_{3}$. Ferroelectrics 1978, 21, 461462.

(30) Zhu, B.; Schusteritsch, G.; Lu, P.; MacManus-Driscoll, J. L.; Pickard, C. J. Determining Interface Structures in Vertically Aligned Nanocomposite Films. APL Mater. 2019, 7, No. 061105.

(31) Chadwick, A. V.; Poplett, I. J. F.; Maitland, D. T. S.; Smith, M. E. Oxygen Speciation in Nanophase $\mathrm{MgO}$ from Solid-State ${ }^{17} \mathrm{O}$ NMR. Chem. Mater. 1998, 10, 864-870.

(32) Wang, M.; Wu, X.-P.; Zheng, S.; Zhao, L.; Li, L.; Shen, L.; Gao, Y.; Xue, N.; Guo, X.; Huang, W.; et al. Identification of Different Oxygen Species in Oxide Nanostructures with ${ }^{17} \mathrm{O}$ Solid-State NMR Spectroscopy. Sci. Adv. 2015, 1, No. e1400133.

(33) Hope, M. A.; Halat, D. M.; Magusin, P. C. M. M.; Paul, S.; Peng, L.; Grey, C. P. Surface-Selective Direct ${ }^{17} \mathrm{O}$ DNP NMR of $\mathrm{CeO}_{2}$ Nanoparticles. Chem. Commun. 2017, 53, 2142-2145.

(34) Li, Y.; Wu, X.-P.; Jiang, N.; Lin, M.; Shen, L.; Sun, H.; Wang, Y.; Wang, M.; Ke, X.; Yu, Z.; et al. Distinguishing Faceted Oxide Nanocrystals with ${ }^{17} \mathrm{O}$ Solid-State NMR Spectroscopy. Nat. Commun. 2017, 8, No. 581.
(35) Hope, M. A.; Halat, D. M.; Lee, J.; Grey, C. P. A ${ }^{17} \mathrm{O}$ Paramagnetic NMR Study of $\mathrm{Sm}_{2} \mathrm{O}_{3}, \mathrm{Eu}_{2} \mathrm{O}_{3}$, and $\mathrm{Sm} / \mathrm{Eu}$-Substituted $\mathrm{CeO}_{2}$. Solid State Nucl. Magn. Reson. 2019, 102, 21-30.

(36) McCarty, R. J.; Stebbins, J. F. Transition Metal Dopant Cation Distributions in $\mathrm{MgO}$ and $\mathrm{CaO}$ : New Inferences from Paramagnetically Shifted Resonances in ${ }^{17} \mathrm{O},{ }^{25} \mathrm{Mg}$, and ${ }^{43} \mathrm{Ca}$ NMR Spectra. J. Phys. Chem. C 2016, 120, 11111-11120.

(37) Fuda, K.; Kishio, K.; Yamauchi, S.; Fueki, K. Study on Vacancy Motion in $\mathrm{Y}_{2} \mathrm{O}_{3}$-Doped $\mathrm{CeO}_{2}$ by ${ }^{17} \mathrm{O}$ NMR Technique. J. Phys. Chem. Solids 1985, 46, 1141-1146.

(38) Panchmatia, P. M.; Orera, A.; Rees, G. J.; Smith, M. E.; Hanna, J. V.; Slater, P. R.; Islam, M. S. Oxygen Defects and Novel Transport Mechanisms in Apatite Ionic Conductors: Combined ${ }^{17} \mathrm{O}$ NMR and Modeling Studies. Angew. Chem., Int. Ed. 2011, 50, 9328-9333.

(39) Halat, D. M.; Dervişoğlu, R.; Kim, G.; Dunstan, M. T.; Blanc, F.; Middlemiss, D. S.; Grey, C. P. Probing Oxide-Ion Mobility in the Mixed Ionic-Electronic Conductor $\mathrm{La}_{2} \mathrm{NiO}_{4+\delta}$ by Solid-State ${ }^{17} \mathrm{O}$ MAS NMR Spectroscopy. J. Am. Chem. Soc. 2016, 138, 1195811969.

(40) Seymour, I. D.; Middlemiss, D. S.; Halat, D. M.; Trease, N. M.; Pell, A. J.; Grey, C. P. Characterizing Oxygen Local Environments in Paramagnetic Battery Materials via ${ }^{17} \mathrm{O}$ NMR and DFT Calculations. J. Am. Chem. Soc. 2016, 138, 9405-9408.

(41) Adler, S. B.; Smith, J. W.; Reimer, J. A. Dynamic Monte Carlo Simulation of Spin-Lattice Relaxation of Quadrupolar Nuclei in Solids. Oxygen-17 in Yttria-Doped Ceria. J. Chem. Phys. 1993, 98, 7613-7620.

(42) Ashbrook, S. E.; Smith, M. E. Solid State ${ }^{17}$ O NMR-an Introduction to the Background Principles and Applications to Inorganic Materials. Chem. Soc. Rev. 2006, 35, 718-735.

(43) Lu, D.; Baek, D. J.; Hong, S. S.; Kourkoutis, L. F.; Hikita, Y.; Hwang, H. Y. Synthesis of Freestanding Single-Crystal Perovskite Films and Heterostructures by Etching of Sacrificial Water-Soluble Layers. Nat. Mater. 2016, 15, 1255-1260.

(44) Liang, X.; Sperling, B. A.; Calizo, I.; Cheng, G.; Hacker, C. A.; Zhang, Q.; Obeng, Y.; Yan, K.; Peng, H.; Li, Q.; et al. Toward Clean and Crackless Transfer of Graphene. ACS Nano 2011, 5, 9144-9153.

(45) Harris, R. K. NMR Crystallography: The Use of Chemical Shifts. Solid State Sci. 2004, 6, 1025-1037.

(46) Johnston, K. E.; Griffin, J. M.; Walton, R. I.; Dawson, D. M.; Lightfoot, P.; Ashbrook, S. E. ${ }^{93} \mathrm{Nb}$ NMR and DFT Investigation of the Polymorphs of $\mathrm{NaNbO}_{3}$. Phys. Chem. Chem. Phys. 2011, 13, 7565 .

(47) Hofstetter, A.; Balodis, M.; Paruzzo, F. M.; Widdifield, C. M.; Stevanato, G.; Pinon, A. C.; Bygrave, P. J.; Day, G. M.; Emsley, L. Rapid Structure Determination of Molecular Solids Using Chemical Shifts Directed by Unambiguous Prior Constraints. J. Am. Chem. Soc. 2019, 141, 16624-16634.

(48) Pickard, C. J.; Needs, R. J. Ab Initio Random Structure Searching. J. Phys. Condens. Matter 2011, 23, No. 053201.

(49) Oldfield, E.; Coretsopoulos, C.; Yang, S.; Reven, L.; Lee, H. C.; Shore, J.; Han, O. H.; Ramli, E.; Hinks, D. ${ }^{17} \mathrm{O}$ Nuclear-MagneticResonance Spectroscopic Study of High- $T_{c}$ Superconductors. Phys. Rev. B 1989, 40, 6832-6849.

(50) Bastow, T. J.; Dirken, P. J.; Smith, M. E.; Whitfield, H. J. Factors Controlling the ${ }^{17} \mathrm{O}$ NMR Chemical Shift in Ionic Mixed Metal Oxides. J. Phys. Chem. A 1996, 100, 18539-18545.

(51) Bastow, T. J.; Stuart, S. N. ${ }^{17}$ O NMR in Simple Oxides. Chem. Phys. 1990, 143, 459-467.

(52) Blinc, R.; Laguta, V. V.; Zalar, B.; Itoh, M.; Krakauer, H. ${ }^{17} \mathrm{O}$ Quadrupole Coupling and the Origin of Ferroelectricity in Isotopically Enriched $\mathrm{BaTiO}_{3}$ and $\mathrm{SrTiO}_{3}$. J. Phys. Condens. Matter 2008, 20, No. 085204.

(53) Zhou, L.; Leskes, M.; Liu, T.; Grey, C. P. Probing Dynamic Processes in Lithium-Ion Batteries by in Situ NMR Spectroscopy: Application to $\mathrm{Li}_{1.08} \mathrm{Mn}_{1.92} \mathrm{O}_{4}$ Electrodes. Angew. Chem., Int. Ed. 2015, 54, $14782-14786$.

(54) Recchia, C. H.; Gorny, K.; Pennington, C. H. GaussianApproximation Formalism for Evaluating Decay of NMR Spin Echoes. Phys. Rev. B 1996, 54, 4207-4217. 
(55) Viefhaus, T.; Bolse, T.; Müller, K. Oxygen Ion Dynamics in Yttria-Stabilized Zirconia as Evaluated by Solid-State ${ }^{17} \mathrm{O}$ NMR Spectroscopy. Solid State Ionics 2006, 177, 3063-3068.

(56) Van Laethem, D.; Deconinck, J.; Hubin, A. Multiscale Modeling of the Ionic Conductivity of Acceptor Doped Ceria. J. Eur. Ceram. Soc. 2020, 40, 2404-2416.

(57) Xu, X.; Liu, Y.; Wang, J.; Isheim, D.; Dravid, V. P.; Phatak, C.; Haile, S. M. Variability and Origins of Grain Boundary Electric Potential Detected by Electron Holography and Atom-Probe Tomography. Nat. Mater. 2020, 19, 887-893.

(58) Kudo, T.; Obayashi, H. Mixed Electrical Conduction in the Fluorite-Type $\mathrm{Ce}_{1-\mathrm{x}} \mathrm{Gd}_{\mathrm{x}} \mathrm{O}_{2-\mathrm{x} / 2}$. J. Electrochem. Soc. 1976, 123, 415.

(59) Bielecki, A.; Burum, D. P. Temperature Dependence of ${ }^{207} \mathrm{~Pb}$ MAS Spectra of Solid Lead Nitrate. An Accurate, Sensitive Thermometer for Variable-Temperature MAS. J. Magn. Reson., Ser. A 1995, 116, 215-220.

(60) Massiot, D.; Fayon, F.; Capron, M.; King, I.; Le Calvé, S.; Alonso, B.; Durand, J.-O.; Bujoli, B.; Gan, Z.; Hoatson, G. Modelling One- and Two-Dimensional Solid-State NMR Spectra. Magn. Reson. Chem. 2002, 40, 70-76.

(61) Clark, S. J.; Segall, M. D.; Pickard, C. J.; Hasnip, P. J.; Probert, M. J.; Refson, K.; Payne, M. C. First Principles Methods Using CASTEP. Z. Kristallogr. - Cryst. Mater. 2005, 220, 567-570.

(62) Perdew, J. P.; Ruzsinszky, A.; Csonka, G. I.; Vydrov, O. A.; Scuseria, G. E.; Constantin, L. A.; Zhou, X.; Burke, K. Restoring the Density-Gradient Expansion for Exchange in Solids and Surfaces. Phys. Rev. Lett. 2008, 100, No. 136406.

(63) Yates, J. R.; Pickard, C. J.; Mauri, F. Calculation of NMR Chemical Shifts for Extended Systems Using Ultrasoft Pseudopotentials. Phys. Rev. B 2007, 76, No. 024401.

(64) Pickard, C. J.; Mauri, F. All-Electron Magnetic Response with Pseudopotentials: NMR Chemical Shifts. Phys. Rev. B 2001, 63, No. 245101.

(65) Larsen, A. H.; Mortensen, J. J.; Blomqvist, J.; Castelli, I. E.; Christensen, R.; Dułak, M.; Friis, J.; Groves, M. N.; Hammer, B.; Hargus, C.; et al. The Atomic Simulation Environment-a Python Library for Working with Atoms. J. Phys. Condens. Matter 2017, 29, No. 273002.

(66) Pizzi, G.; Cepellotti, A.; Sabatini, R.; Marzari, N.; Kozinsky, B. AiiDA: Automated Interactive Infrastructure and Database for Computational Science. Comput. Mater. Sci. 2016, 111, 218-230.

(67) Momma, K.; Izumi, F. VESTA 3 for Three-Dimensional Visualization of Crystal, Volumetric and Morphology Data. J. Appl. Crystallogr. 2011, 44, 1272-1276. 